Journal of Southeast Asian

\title{
Identities Development of Adult Chinese Heritage Language Learners from Southeast Asian American Families
}

Feng Liang

Wittenberg University, liangf@wittenberg.edu

Follow this and additional works at: https://docs.lib.purdue.edu/jsaaea

Part of the Bilingual, Multilingual, and Multicultural Education Commons, and the Modern Languages Commons

\section{Recommended Citation}

Liang, Feng (2021) "Identities Development of Adult Chinese Heritage Language Learners from Southeast Asian American Families," Journal of Southeast Asian American Education and Advancement: Vol. 16 : Iss. 1, Article 18.

DOI: $10.7771 / 2153-8999.1234$

Available at: https://docs.lib.purdue.edu/jsaaea/vol16/iss1/18

This document has been made available through Purdue e-Pubs, a service of the Purdue University Libraries. Please contact epubs@purdue.edu for additional information.

This is an Open Access journal. This means that it uses a funding model that does not charge readers or their institutions for access. Readers may freely read, download, copy, distribute, print, search, or link to the full texts of articles. This journal is covered under the CC BY-NC-ND license. 
Identities Development of Adult Chinese Heritage Language Learners from Southeast Asian American Families

\section{Cover Page Footnote}

I appreciate the feedback and efforts of the reviewers and editorial team. 


\title{
JSAAEA Journal of Southeast Asian American Education and Advancement
}

Vol. 16 Iss. 1 (2021)

WWW.JSAAEA.org

\section{Identities Development of Adult Chinese Heritage Language Learners from Southeast Asian American Families}

\author{
Feng Liang \\ Wittenberg University
}

\begin{abstract}
Although linguistic and cultural varieties exist among Chinese Heritage Language Learners (CHLLs), little attention has been given to how adult CHLLs with non-Mandarin backgrounds attempt to negotiate their identities when they learned Chinese. Grounded in He's $(2008,2016)$ theory of Chinese heritage language (CHL) development, this study explored the construction of identities of Chinese adults from Southeast Asian American families in the process of Chinese heritage language learning. Three adult CHLLs in the United States participated in a multiple-case study that lasted for six months. Data collection included interviews, journals, observations, and informal communications. Findings suggest that CHLLs with Southeast Asian family backgrounds had a deeper understanding of their identity during adulthood and tended to construct an identity that was opposite to the group with which they were interacting. Highlighting the heterogeneity and fluidity of the identities among participants, this study concludes with implications.
\end{abstract}

Keyword: Heritage Language, Identity Construction, Chinese, Language Learning, Language Use and Identity

\section{Introduction}

There are a lot of varieties among Chinese heritage language learners (CHLLs) in terms of their identities, individual experiences, Chinese language use, and length of formal Chinese instructions. Even though this group is labeled as CHLLs, they are heterogeneous in terms of their backgrounds and identities (Weger-Guntharp, 2006).

Although the research on heritage language (HL) education has gained certain attention and has been developing as a specific field of academic investigation (e.g., Brinton et al., 2008; He \& Xiao, 2008), there is limited literature available on CHLLs at the post-secondary level or after (e.g., Carreira \& Kagan, 2018; Duff et al., 2017). This group of CHLLs may still advance or cease their development or maintenance of their Chinese identity, with their (un)change of investment and identity compared to their childhood.

Learning an HL is inseparable from identity construction and the learners' identity has become an integral part of HL research (e.g., Blackledge et al., 2008; Duff et al., 2017). This indicates that the mission of HL education should not only concentrate on improving learners' language proficiency but also pay more attention to how to help them foster and understand their identity (Xiang, 2016). Heritage language learners' identity lies in how they position 
themselves and others, and it is also influenced by how others view them. The reason is that heritage language learners' identities are socially constructed through interaction with others (Hornberger \& Wang, 2008; Norton, 2013). During Chinese language learning or use, adult CHLLs may also constantly search for or reconstruct a deeper understanding of who they are, who they expect to be, what they want to be identified as, and how they relate to the world. However, there is very little information available on how adult CHLLs perceive themselves in different contexts. As another facet of identity construction (Hornberger \& Wang, 2008), more in-depth discussions on how adult CHLLs are perceived by others are needed because others' positioning on CHLLs is likely to affect the way how CHLLs view themselves (Hornberger, 2012).

The purpose of this study is to explore how adult CHLLs with non-Mandarin backgrounds (re)construct their identities in the process of Chinese heritage language learning over time from childhood to adulthood. Research questions include:

1. How did CHLLs construct and reconstruct their identities in their childhood?

2. How did CHLLs' identity develop when they took the Chinese course in college?

3. How did CHLLs reconstruct their identities after they finished the Chinese course or graduated?

\section{Theoretical Framework}

He (2008) claims that "the question of identity may be a key to CHL development" (p. 117). CHL development is a socialization process that shapes and is shaped by CHLLs' identities and goals with multiple directions (He, 2012). He's CHL framework generally probes two questions: (a) How CHLLs identify themselves and (b) how CHL development happens and is sustained.

Answering the first question, He argues that the construction and development of learners' situated identity is their chief impetus to learn CHL (e.g., He, 2008). In contrast to viewing identity as "a collection of static attributes" (He, 2012, p. 595), He proposes that identity should be understood as a process that emerges and is constructed in and through human interactions (He, 2014). The CHLLs, as is considered by He (2008), will continuously build, assess, adjust, and change their identities across different settings and life stages. He also raises three identity-wise hypotheses of CHL development. First, whether the CHLLs can find their position in the dominant language community linguistically, culturally, and/or socially will affect their CHL development (enrichment hypothesis). Second, CHL development also depends on whether the CHLLs can manage their multiple and sometimes competing identities across different contexts such as school, family, peer groups, and community. Third, He asserts that CHLLs can not only be socialized into the target community through learning and using Chinese but also can socially influence the target culture and community.

Regarding CHL development, this framework posits that the process of learning and using CHL depends on time, space, and identity. To elaborate, He contends that CHL development (a) is shaped by past, current, and future experiences, (b) transcends spatial limits to larger and interdependent communities, and (c) is "contingent on the degree to which the learner is able to construct continuity and coherence of identity in multiple communicative and social worlds" (He, 2008, p. 5). 


\section{Literature Review}

\section{Young CHLLs before College}

Young CHLLs' identity construction is connected to many factors, including birthplace, physical appearance, lifestyle, family's origin, and Chinese fluency. Liu (2008) found that having Chinese features is not the main reason for young CHLLs to claim their Chinese identity. Nearly half of the participants in Liu's (2008) study of Chinese language learning for heritage learners believed that being Chinese meant a person came from China. Likewise, many secondgeneration CHLLs associate their identity more with their ethnic origin before their adulthood. However, they do not typically form a close connection to their cultural heritage (Kurniawan \& Suprajitno, 2019).

In Liu's (2008) study, the proportion of those who identified themselves as more Chinese or full Chinese (43\%) was the same as the proportion of those who considered themselves as half Chinese and half American (43\%). The other 14\% considered themselves more American. To add to the discussion, Liang and Shin (2021) interviewed four young CHLLs and found that all of them considered themselves to be part Chinese and part American. Their reasons were similar to each other. These CHLLs were born and grew up in the United States and thus they considered themselves as part American. Meanwhile, their family was from China and thus these CHLLs also identified themselves as part Chinese.

Chinese fluency is linked closely to how Chinese a person is (Francis et al., 2014; Kim $\&$ Chao, 2009). By analyzing the survey results from 63 American-born Chinese children at a community CHL school, Yu (2015) showed a statistically significant relationship between Chinese heritage language proficiency and ethnic identity. Francis et al. (2014) found that a large majority of young CHLLs (95\%) held that as Chinese people, they should learn and be able to speak Chinese. This language ideology of perceiving language proficiency as central to ethnic identification makes learners develop a belief of moral responsibility for learning Chinese. Otherwise, young CHLLs would feel embarrassed or ashamed if they don't know how to speak Chinese (Francis et al., 2014). Kim and Chao (2009) added that this assumption was only perpetuated among first-generation Chinese immigrants. For the second generation of CHLLs who spent most or all of their lifetime in the United States, they valued English more than Chinese. Along with the fact that they can hardly improve their Chinese proficiency due to limited exposure, these CHLLs still have a strong sense of ethnic identity. Hence, the researchers argued that HL fluency did not necessarily determine the ethnic identity of young second-generation CHLLs, as they stated that "using heritage language fluency to assess the ethnic identity scores of second-generation Chinese adolescents may artificially deflate their ethnic identity scores" (Kim \& Chao, 2009, p. 35).

\section{How Adult CHLLs Construct Their Identity}

CHLLs' identity after high school is studied along with different social contexts, motivation, learners' dialect background, and their Chinese learning. Mu (2016) conducted a mixed methods research to unveil the complexity between Chinese ethnic identity and CHL development. Through quantitative analysis, the researcher found that variables such as participants' $(\mathrm{N}=230)$ perception of their Chinese appearance and others' perception and expectation of the participants to speak Chinese are statistically significant to CHLLs' improvement of HL proficiency. Additionally, language-use patterns at home and the age of immigration were also significant predictors for their Chinese proficiency. Qualitative results from interviews further corroborated the quantitative results, suggesting that looking Chinese shaped CHLLs' identity and drove them to learn Chinese willingly or unwillingly. This 
research concludes that as a complex process with construction and negotiation of identities, "CHL learning is neither fully dependent on, nor completely free of, Chinese looks" (Mu, 2016, p. 303).

Dai and Zhang (2008) investigated what CHL learners inherited from their upbringings and experiences linguistically, culturally, and socially. The study found that a majority of CHLLs identified themselves as being influenced by both Chinese and American cultures. This identity construction might lead to either complementary or conflicted consequences in certain contexts when they were interacting with others such as parents and teachers. For example, CHLLs might have conflicts with their parents in such moments as deciding an academic major, buying cars, and planning for the future, because of the discrepancy of cultural habitus between CHLLs and their parents.

Li and Duff (2014) conducted a longitudinal study of CHLLs' development of identities and found that participants demonstrated "ambivalence, desires, pressures, positionings, and struggles" (p. 234) in the process of Chinese learning in different contexts including home, school, and community. Meanwhile, when their Chinese proficiency grew, they felt confident, stimulated, and socially connected. For example, one of the participants was originally from a multilingual family. She had a non-Chinese appearance because her father was from Denmark and her mother was from Hong Kong. The participant spent her life in different cities around the world. She was more fluent in Danish and Cantonese than Mandarin. She learned Mandarin Chinese when she was young and now at the university and liked the sound of Mandarin. This participant highlighted the sense of cultural affiliation and connection to Chinese culture and tradition as the driving force to learn Chinese. She expressed that the process of learning CHL enabled her to "understand what kind of person I am and that I know I am Chinese" (Li \& Duff, p. 232). Besides, this participant also felt more confident as her proficiency in Chinese grew. Therefore, learning Chinese has provided affordances to this CHLL to affirm and enhance the Chinese part of her multifaceted identity.

Weger-Guntharp (2006) investigated how contrasting identities experienced by eight CHLLs shaped their classroom CHL learning. The researcher employed both quantitative and qualitative methods. Quantitative results showed that all participating CHLLs regarded their heritage status as one of the reasons for their enrollment to the Chinese class to reclaim their cultural identity. Recognizing their ethnic identity as a resource, CHLLs believed that learning and enhancing Chinese could gain economic and academic benefits in the future. Therefore, CHLLs' heritage status played a vital role in constructing their identity. Moreover, although CHLLs had become adults, their identity was still influenced by their family members who explicitly or implicitly expected their children to maintain the HL. In this sense, CHLLs' social identity is struggling between adult independence and familial dependence (Weger-Guntharp, 2006).

In addition, Weger-Guntharp (2006) found that CHLLs were willing to cooperate with other classmates including non-CHLLs. Conversely, the attitudes of non-CHLLs on working with CHLLs were diverse. Some non-CHLLs expressed a sense of discomfort being grouped with CHLLs. Weger-Guntharp (2006) speculated that this feeling of unease stemmed from non-CHLLs' perception that CHLLs were more powerful and advantageous with Chinese heritage background. Besides, CHLLs had more opportunities to interact with Chinese instructors after class. However, CHLLs considered that instructors tended to have higher expectations toward them. Weger-Guntharp (2006) thus concluded that CHLLs' perception of self, peers, and teachers will impact the development and expression of their ethnic identities. She went further to propose that learners' struggling identities should be carefully considered especially for those HLLs with low proficiency in Chinese who may self-identify as foreign language learners. 


\section{HL Learning and Identity: Southeast Asian American Students}

Several Southeast Asian HLs in the United States, including Khmer, Vietnamese, and Hmong, have been experiencing a generational decline (e.g., Lao \& Lee, 2009; Tran, 2008; Withers, 2004; Wright, 2010; Yang, 2008). Take Khmer as an example, researchers found that not only did students of Khmer heritage have decreasing proficiency of Khmer; their literacy skills also developed slowly compared to oral skills (Lao \& Lee, 2009; Wright, 2010). Furthermore, students' English development was significantly higher than their HL skills (Lao \& Lee, 2009). Hmong parents usually came across resistance from their children in maintaining the Hmong language. Their children thought Hmong is useless in the United States and the children did not want their parents to interfere with their learning. It makes it even harder for maintaining Hmong when it comes to the insufficient Hmong educational resources (Yang, 2008).

Enrolling in a community-based heritage language program is one of the major ways to counter the trend of language shift and promote HL learning for children. It yet encountered various challenges. For example, there is a lack of Khmer HL programs both in quantity and quality, particularly under the English-only instruction context (Wright, 2010; also see Maloof et al., 2006). Vietnamese programs also experienced similar limitations in terms of funding, personnel, teachers' expertise, instructional materials, and so forth (Tran, 2008). Maloof et al. (2006) further revealed that HL schooling experience had little impact on students' cultural identity. What matters more are their age of arrival in the United States and their family environment such as how Vietnamese language and culture were cultivated in their homes.

Studies did show some positive aspects regarding heritage language maintenance and identity construction in Southeast Asian HLs (e.g., Maloof et al., 2006; Marks et al., 2007; Tran, 2008; Wright, 2010). In terms of Vietnamese HL learning, Maloof et al. (2006) indicated that community-based HL schools played an important role in improving students' Vietnamese proficiency and frequency of use. Through demographic analyses, Wright (2010) argued that Khmer language is "alive and well" (p. 134). A large proportion of Cambodian Americans reside in several major metropolitan areas and therefore have more opportunities to communicate with their ethnic peers in their heritage language regularly (see also Lao \& Lee, 2009); young Cambodian Americans "are still speakers of their home language" (p. 135). Participants in Lao \& Lee (2009) further reported that they used Khmer frequently at home. Moreover, Marks et al. (2007) suggested that children of Cambodian heritage started to develop an ethnic identity with positive attitudes and pride, especially for older children. Wright (2007) noticed that Cambodian Americans are constructing a new identity that places less emphasis on Khmer language proficiency.

\section{Method}

\section{Research Site and Participants}

This study was part of a larger qualitative multiple-case study, with its focus on in-depth understanding, meanings, contexts, and process (Yin, 2014, 2015). Three adult CHLLs, namely Andrew, Gabe, and Allan, participated in this study and agreed to use their real names (see Table 1). They all have a certain extent of Southeast Asian ancestral background. Allan's maternal grandparents can speak both Mandarin and Vietnamese. They immigrated from Laos to Vietnam and finally to the United States. Allan's mother was born in Laos. Allan's paternal grandparents immigrated to Malaysia from China, and his father went to the United States to study, where he met Allan's mother. Allan's parents can both speak fluent Mandarin.

Andrew's maternal grandparents lived in Cambodia, but both of them were ethnically Chinese. Andrew's mother grew up speaking Chaozhou dialect (a Chinese local dialect) and 
Cambodian. His paternal grandmother was Cambodian, and his grandfather was from China. Therefore, Andrew's father was half-Chinese by blood. However, his father just speaks Cambodian and English. Andrew's parents have lived in the United States for more than 40 years.

Gabe's paternal ancestors were ethnically Hmong in China. They moved to Laos where Gabe's father and grandfather were born. Then they migrated from Laos to the United States where Gabe was born. Gabe's mother was American with German heritage.

This study was mainly conducted at a major university in the midwestern United States where Gabe and Allan studied. Andrew had already graduated and worked in another major city on the east coast. All of them had previously completed community-level and college-level Chinese classes.

Table 1

\begin{tabular}{lllll}
\multicolumn{2}{l}{ Summary of Participants } & & \\
\hline Name & Gender & Age & Family languages & Current job \\
\hline Andrew & Male & 33 & Cambodian, Chaozhou dialect, English & Copywriter \\
Allan & Male & 20 & Mandarin, English & Student \\
Gabe & Male & 24 & Hmong, English & Student \\
\hline
\end{tabular}

\section{Data Sources}

Informed by the qualitative data collection principles for case study (Merriam, 2010; Yin, 2014), I collected four domains of data: Interviews and journals as primary sources, and observations and informal communications as supplementary data. Field notes were made during observation. Multiple sources of data not only enable a rich description and intensive understanding of the cases but also enhance rigor and credibility (e.g., Yin, 2014). For each participant, data collection lasted at least six months, with different starting and ending dates depending on their schedule.

I individually conducted semi-structured interviews three times with each CHLL to gain rich data (DiCicco-Bloom \& Crabtree, 2006; Hesse-Biber \& Leavy, 2011). Each interview took about one hour. The first interview was conducted at the beginning of data collection. This interview took place before the participants started to write their journal entries because I could orally explain to them how and what to write about. The second interview was scheduled at the halfway point after I had collected and preliminarily analyzed some of the data. In this way, I could member-check with the participants and develop interview questions based on my initial analysis (Maxwell, 2013). The third interview was before the conclusion of data collection. The form of the interview was organized mainly by open-ended questions with flexibility for emerging questions from the conversation (DiCicco-Bloom \& Crabtree, 2006).

Every two to three weeks, the participants were asked to narrate their experiences related to Chinese language learning, Chinese culture, and Chinese use in journal entries using English. The story could have happened in participants' childhood, after they entered college, or recently.

Observation enabled me to collect data in a more naturalistic and unstructured setting. It can also be helpful to identify whether there were discrepancies among different data sources (Mulhall, 2003). The observation took between half an hour to three hours and focused on the participants' language practices in their everyday life, especially when they communicated with their Chinese language speakers. For example, I observed the interaction between a participant and his girlfriend during lunch at a restaurant.

I used emails or other social media in a casual way to clarify or have my participants elaborate certain topics that were discussed during our interviews or expressed in their journal 
entries. By staying connected with the participants, I had a better sense of the development of their identities as well as identifying information that had not been mentioned in the interviews or journal entries. The finding then became much richer and the trustworthiness of the inferences was strengthened (Yin, 2013).

\section{Data Analysis}

Thematic analysis (e.g., Nowell et al., 2017), "a method for identifying, analyzing and reporting patterns (themes) within data" (Braun \& Clarke, 2006, p. 79), was employed. Before generating initial codes, I read through the texts several times and wrote memos simultaneously to document my initial thoughts, reminders, and reflections (Creswell, 2013). Writing memos reminded me of things that I needed to pursue and emphasize in my later data collection (Merriam, 2010). Then, I conducted open coding by using labels to group and summarize similar events/actions/interactions for emerging themes (Corbin \& Strauss, 2015). After that, I conducted axial coding by combining the open codes into tentative categories "based on how different codes are related and linked" (Hsieh \& Shannon, 2005, p. 1729). In other words, I grouped those relevant open codes. Axial coding helped me narrow down a large number of open codes deductively into categories that were theoretically grounded in my data. Following axial coding, I conducted selective coding by which all the relevant categories were selectively aggregated to adequately represent all of the open codes (Corbin \& Strauss, 2015). Therefore, selective codes were potential themes that were abstracted because they need to theoretically summarize the range of finding categories identified in previous steps. This coding is across cases. Finally, in light of the codes, each case was stated in three stages of the CHLL participants' lives: childhood before college, during college, and after graduating or after college Chinese class, with sufficient evidence and typical examples that linked to the themes. Such an organization can intensively describe how CHLLs' identities were constructed over time. Cross-case analysis was then presented in the discussion section (Yin, 2014).

\section{Findings}

\section{Andrew's Case}

\section{Childhood}

Andrew's identity in childhood was represented by three separated but overlapping circles, namely Chaozhou, Cambodian, and American. Andrew contended that these three overlapping identities looked like a photo, with something in focus and something blurry in the background. Yet they all existed whether clear or blurry. Andrew felt more as a Chaozhou person particularly when he stayed in his grandma's house. When he was at home with his parents, he thought of himself more as Cambodian, but more as American when he was in school. These were the occasions when one single part of the identity was prominent. On other occasions such as when he was with his parents in public, Andrew probably felt both Cambodian and American identities.

Moreover, Andrew exercised his agency to assert his identity in different contexts. He did not feel struggling with these three identities because his upbringing was different from some people who grew up in a predominantly single-racial neighborhood. "Until I was 13, I grew up around a lot of Asian Americans, so I felt pretty normal ... It didn't cause any conflicts" (Andrew Interview 2, July 25). Moreover, Andrew had varied emphasis on his identity when he interacted with different people. When other people asked where he was from, Andrew would respond exactly with the name of the city where he was born and grew up. Because his 
parents immigrated from Cambodia, Andrew always identified himself as Cambodian American, especially when he interacted with white or black American people. The reason was that Andrew did not want to explain too much about his heritage and ancestry. When interacting with other Asian American people such as Chinese classmates, Andrew would identify himself as partially Chinese because he spoke one of the Chinese dialects. Although Andrew acknowledged the Chinese part of his identity, he never said he was Chinese. He used the word "Chaozhou" rather than "Chinese." "When I was a kid, actually, there were a lot of Chaozhou people around" (Andrew Interview 1, April 8). If Andrew was with people who spoke the Chaozhou dialect, he would identify himself as Chaozhou people. However, Andrew did not speak the Chaozhou dialect to these people because he knew English more than the Chaozhou dialect. He could hardly have an in-depth conversation with these people if he spoke only the Chaozhou dialect.

\section{College}

Rather than the Chaozhou dialect, Andrew chose to learn Mandarin for its useful and practical values. There is an assumption that the language people learn as a heritage language is the one that is spoken in the family. However, Andrew's father did not speak Mandarin and maternal family members mainly spoke the Chaozhou dialect. "It feels disconnected from my family ... I think of Chaozhou as more of my family and Mandarin as more of something that is useful in the world and more practical" (Andrew Interview 2, July 25). Andrew believed that the major difference between him and other students without Chinese heritage in the Chinese class was his ancestral background and Stella, his Chinese-speaking girlfriend. He always thought he would need this language in the future, and it had become a "responsibility" for him (Andrew Interview 3, October 18), while other non-CHLLs chose Chinese out of any other languages without having a family reason to consider.

Similar to his childhood, Andrew reconstructed his identity in a way that was opposite to the group he interacted with, which was caused by both his personality and others' positions. Specifically, when Andrew was around a lot of American people, he usually thought of how non-American he was. When Andrew interacted with Chinese people, he felt more American than Chinese. Andrew valued uniqueness more than commonness. He was more interested in how he was different more than how many commonalities he shared with other groups of people. He found himself different from the Chinese people he met in terms of the way he acted, the way he spoke, and the way he thought. Although some of them became his close friends, it did not necessarily make Andrew feel more Chinese. Conversely, Andrew was more aware of how American he was under this circumstance. This American identity was also shaped by his Chinese friends' positioning on him. For example, after they got to know each other more, Andrew's Chinese friends thought of him as 100\% American rather than Chinese. This experience indirectly influenced Andrew's identity construction. "It actually made me feel more American," noted Andrew (Andrew Interview 2, July 25).

\section{After College}

After graduation, Andrew's identity was composed of four parts, including American, Asian American, Cambodian- or Chaozhou-American, and Chinese American. He felt it was normal and without struggles to claim multiple identities. The first major part of Andrew's identity was American. "I was born in America and grew up in America, so my behavior, customs, and values are very based on American society," explained Andrew (Andrew Journal 8, October 17). His mother thought of him as American because he could not speak Chinese nor act in a Chinese way such as making Chinese food. Especially from spending time with Stella and her 
family, Andrew learned that he did not practice many Chinese customs and his values were "only somewhat" aligned with Chinese people (Andrew Journal 8, October 17).

The second part of his identity was Asian American because Andrew cared deeply about the political issues that happened to Asians in America, particularly the racial discrimination experienced by many Asian Americans. Andrew realized that neither he nor his family knew much about the current Chinese or Chinese American culture. His parents were often surprised by how different Stella's parents were from their expectations of Chinese people.

The third composition of Andrew's identity was Chaozhou American or Cambodian American because of his upbringing. Different from his mother's and brother's preference to use the broader term Chinese when talking about identity, Andrew thought of himself as more Chaozhou than Chinese. This is related to his ancestral migrating history and the language spoken by his family members. He felt more of Southeast Asian Chinese with a Chinese ancestral background than a pure mainland Chinese. Moreover, his family language was not Mandarin, which is the main language in China.

Also, Andrew thought of himself as Cambodian American because his parents lived in Cambodia for twenty years. They could speak Cambodian and observed Cambodian traditions. Andrew thought it is worth connecting to Cambodian identity. However, neither his mother nor brother tended to embrace the Cambodian identity. His brother argued that "it's weird to have Cambodian identity, since we don't have much of the blood" (Andrew Journal 3, June 12). His mother attached negative images to Cambodian people such as poor, lazy, and alcoholic, and thus she did not identify Andrew as Cambodian. Contrary to his mother, Andrew did not think all Cambodian immigrants were in that situation. His identity was then reconstructed socially toward a more prominent Cambodian identity.

The last part of Andrew's identity was Chinese American. Andrew did not think of himself as very Chinese, because he "was several generations away from China" (Andrew Journal 5, August 27). That was why he put the Chinese American identity to the last part with the least weight. His brother thought Andrew was Chinese because their mother was 100\% Chinese by blood. The family not only celebrated Chinese New Year but also cooked Chinese food. Andrew did not resist his Chinese identity, yet he felt more connected to the China which his ancestors left from around the 1940s to 1950s, instead of the current China. "I don't feel connected to the China of today" (Andrew WeChat, April 10). He asserted that the Chinese people from that period, just like his parents and ancestors, were culturally different from what the Chinese people are currently. Stella's parents considered Andrew to be Tang Ren, a Chinese word that referred to the Chinese immigrants whose ancestors came to America many generations ago and did not speak Chinese fluently. Andrew found that the identity of Tang Ren "seemed reasonable to me[him]" (Andrew Journal 5, August 27).

\section{Gabe's Case}

\section{Childhood}

Gabe identified himself as Asian American in his childhood because he grew up in America, and meanwhile he had both Asian family background and an Asian look. In his journal entry, Gabe mentioned that his experience in a community Chinese school made him know more about Chinese Americans. He said he was "grateful" for experiencing something that many Chinese Americans experienced growing up in this country (Gabe Journal 3, July 4). Specifically, "Chinese weekend school definitely shaped my understanding of Chinese culture and language and how it continues here in America generations later," summarized Gabe (Gabe Journal 3, July 4). 
Gabe had mixed feelings when people always assumed that he was full Asian by look. He was always asked questions such as "Where are you from?" or "Were you born here?" In his opinion, it was by default that if a person has an Asian look, everyone just automatically thinks this person is Chinese. Most of the time, Gabe felt alright about these questions. He seemed to get used to this stereotype. He always replied, "No, I am not Chinese." He felt upset occasionally because he grew up in America, but others always thought he was not from America. Gabe struggled with others' positioning, as he questioned, "Do I need to show you my passport to verify my identity?" (Gabe Interview 1, May 10).

\section{College}

Gabe's position of himself did not change in his college time. He tended to be aware of the contrast from the people around him. In other words, Gabe's American identity was more prominent when he studied abroad in China, while his Asian identity was strengthened when he was in America. That Gabe's behavior and thinking were affected by American culture was more prominent in China, compared to how everyone else thought and acted. For example, Gabe observed that the traffic in China did not like to stop for pedestrians, which was considered to be rude and dangerous in the American view. Under this circumstance, Gabe's American mindset would be more dominant than his Asian counterpart. When Gabe was in America, he "can see how much eastern and Asian or Chinese influence had" in his life (Gabe Interview 1, August 6). One example was that he would never host a birthday party and ask the guests to bring their food. His reaction was that "you're hosting it; this is your thing; you should provide for everybody" (Gabe Interview 1, August 6). That was when Gabe noticed his Asian identity more prominent than the American part.

When sitting in a classroom with other students who studied Chinese as a foreign language rather than a heritage language, Gabe noted that he was different from this group of people in terms of cultural experience. Growing up with Asian grandparents, Gabe believed that there was certain cultural knowledge he came across in the classroom that maybe someone who had no Asian background would not understand as fast. Moreover, he would not feel surprised when he learned about aspects of Chinese culture. "I kind of grew up with that," said Gabe (Gabe Interview 1, August 6), and it was not as weird or crazy for him as it was for other classmates. Gabe mentioned that "in Hmong we have some similar concepts as Chinese" (Gabe Interview 1, August 6). By learning a language that was different from Hmong as his ancestral language, Gabe felt that "it's interesting and funny" (Gabe Interview 2, August 6). Gabe's Hmong was not as good as his Chinese. According to his description, the senior relatives never asked him to learn it, nor did they teach him on purpose. However, Gabe asserted that the older generation should have taught him more.

\section{After College}

Gabe kept his identity as an Asian American after he graduated from undergraduate school. He said, "I think my sense of identity was pretty solidified when I started law school" (Gabe Interview 3, October 21). The reason was that he grew up in the United States and had both an eastern and western background. Besides, Gabe did not identify himself as Chinese American. He explained that his family was born in Laos, and he was told that "Hmong people are not quite the same as Chinese" (Gabe Email, November 27). Lao American or Hmong American were also acceptable as his identity, yet Asian American was probably the most accurate for him (Gabe Journal 8, November 3). There was a lot of nuance to his identity and feelings that were hard to express clearly in one word or phrase. Asian American "is the most straightforward way to convey myself to other people," believed Gabe (Gabe Interview 3, 
October 21). Gabe believed that the better Asian Americans understand Asian culture and American culture, the more possibility there is for well-rounded people to operate flexibly in different contexts. He maintained that people who live in between cultures can take advantage of it in their favor. Personally and professionally, performing the identity of Asian American and learning Chinese thus could be mutually beneficial.

Gabe associated his identity with the pursuit of social justice and equality. It was his Asian American identity that inspired him to get involved in the Asian student organization in law school. Part of the mission of the organization was about the representation and integration of Asian Americans and attorneys of color into the workforce. Since there was a small proportion of attorneys who were Asian Americans in the United States, the main task for him and other Asian American future attorneys was to get engaged in and to be represented in the legal community. Gabe's goal, consistent with the student organization's purpose, was to amplify Asian American attorneys' voices and demands in the broader context.

\section{Allan's Case}

\section{Childhood}

Allan initially thought of himself as just Chinese. He only knew his Chinese heritage background, without knowing that he also had other Asian backgrounds such as Vietnamese and Laotian. After that, he changed his identity as Asian American to include all these components. The reason why he wanted people to identify him as Asian-American was that "I was born and raised in America, but I do still have strong roots to my Asian culture" (Allan Journal 8, October 14). He could not find anything specific or concrete to represent his identity, as Allan claimed that "I am myself and no one else is me" (Allan Interview 1, March 26).

Throughout his life, Allan was occasionally asked by others where he was from and was often mistaken as being from China. To respond to the first question, Allan underscored his American birthplace in English "since that's where I was born and raised" (Allan Journal 2, April 15). Sometimes people would be very surprised or curious about his response. Allan might feel awkward rather than anything harmful because most of the time the conversation was friendly. For example, there was a transfer student from China in Allan's high school. "He was asking me where I am from. I say Lake-city (pseudonym by the author). And he was like OK, where your parents were from, and then at that point I explained" (Allan Interview 3, October 25). Allan laughed and he did not think it was impolite or inappropriate.

However, Allan did experience offensive moments. One such occasion was when he was in high school and he worked at a restaurant as a part-time job. This experience was described in Allan's journal entry and was discussed during the interview. In detail, one night when he was working for someone's wedding party, there was one group that called him over. They had been drinking a lot and asked Allan where he was from. These guests were betting on where Allan was from, to which Allan answered Lake-city. This group of people then asked where he was really from. Allan "got a little offended by that" (Allan Interview 1, March 26) and then he just walked away without further explanation. "They kind of judge me over," said Allan (Allan Interview 1, March 26). He expressed that such an experience was not very pleasant because it was involved with "sort of racism" (Allan Journal 2, April 15). Such negative experiences as this had caused a decline in Allan's passion for learning Chinese because he was afraid of his American identity being overlooked and his identity arbitrarily judged by others. 


\section{College}

Allan kept his identity as an Asian American during college. What had changed was his growing interest in Chinese language and culture, though just a little bit, as he engaged in the Chinese class. The reason was that he wanted to better communicate with his family such as to understand more about what they were saying. Moreover, he learned more about his ancestry. Before college, Allan did not know about the older relatives in the family. He learned more about his grandmother from his mother, such as how his grandmother came to America, from where, and so forth. It is an empowering means to get connected to the heritage culture including its language, food, and everything that makes it unique, as well as to challenge the status quo.

Allan thought that there is a little difference between him and other non-CHLL classmates in terms of prior knowledge of Chinese language and culture. "I have been exposed to Chinese language a little bit more than they have," said Allan (Allan Interview 2, July 23). When I, as the instructor, talked about the cultural notes in the Chinese class, Allan usually shared something which was not written in the textbook. What he talked about always captured other classmates' attention because it was associated with his personal experience as a learner with Chinese heritage background. However, Allan did not think he was different from his classmates in the sense that they were all learning new things.

\section{After Chinese Class}

After finishing the college-level Chinese class for a semester, Allan kept identifying himself as Asian American. Although he also admitted that he is part Chinese, he was inclined to identify as Asian American rather than Chinese American. He asserted that the word Chinese meant being born in China, "like Japanese to Japan and Vietnamese to Vietnam," added Allan (Allan Interview 3, October 25). Allan's ancestry was connected to China but not only to China. It was also connected to other Asian countries such as Vietnam and Laos from his mother's side. After Allan's grandmother moved to America, she lived in a large half-Chinese and halfVietnamese community. Allan's mother and uncle grew up speaking Mandarin and learned it from being exposed to the Chinese community. As for Allan's father, he was born and raised in Malaysia, though Allan's grandparents were born in China. Therefore, the connection to China was "slim" (Allan Interview 3, October 25). Therefore, Allan thought Chinese American does not accurately represent all of his family history and identity. "Asian American would just fit better. It encompasses all of it," said Allan (Allan Interview 3, October 25).

Apart from the Asian part of his identity, Allan emphasized another part of his identity by stating that "I am more of an American because I was born and raised in America" (Allan Interview 3, October 25). Moreover, he did not speak Chinese fluently and nor did he have strong ties to the Chinese culture. Therefore, he felt himself more of an American than other identity components. Allan believed that his birthplace can represent his identity because it is where he was born and raised. It is an American city, while it also has a large Asian community in the urban area. Allan always went there because his parents used to work in that community. "I do love being there," expressed Allan (Allan Interview 3, October 25).

Furthermore, Allan sometimes encountered occasions when he was mistaken for a person from China and could speak fluent Chinese. These people included Chinese people and his American friends. Occasionally, the Chinese people approached Allan and asked him something in Chinese, assuming that Allan could speak Chinese. In his journal entry, Allan recalled that he once bought groceries at an Asian market, and the cashier spoke Chinese to him. Allan just told her that he did not understand, and consequently he promptly checked out in English. Mostly, Allan took a neutral attitude toward these occasions. It was "a pretty 
common occurrence" to Allan's life and he could not "stop it from happening" (Allan Journal 3, May 16). By acknowledging himself as part Chinese, Allan did not think these people are wrong because he admitted that he looks Asian.

\section{Discussion}

Three major themes emerged from the data. First, growing up in different social environments, CHLLs in their childhood had various identity constructions depending on the people they interacted with. Second, CHLLs in college constructed an identity that was opposite to the group with which they were interacting. Third, CHLLs had a deeper understanding of their identity after they entered college than when they were in their childhood.

CHLLs in their childhood tended to enact a different identity according to different people they interacted with. For example, Andrew identified himself as Cambodian American when he interacted with Caucasian- or African-Americans. On other occasions, Andrew identified himself as a Chaozhou person when he spoke to other Asian Americans, although he admitted that he is partially Chinese. The findings revealed that this identity shifting phenomenon was due to CHLLs' situated consideration in different interactive contexts. For instance, Andrew did not want to explain too much about his mixed heritage with other American people. Additionally, he felt more connected to Chaozhou culture than the broader Chinese culture because there were a lot of Chaozhou people around in his childhood.

Growing up in different social environments, the participants had positive or negative feelings toward their identity construction. Andrew felt normal to be exposed to a diverse environment with many Asian-Americans and other racial groups. However, both Allan and Gabe felt awkward when people asked where they came from. Occasionally, they would get upset when their identity was judged by others. As Gabe mentioned, if one had an Asian look, people would assume that this person is Chinese. Therefore, when people got a different answer, they would keep asking and try to confirm, though sometimes this curiosity was not illintentioned. These interactions between CHLL participants and other people reflected how the hidden and unequal societal power relations and dominant ideology are produced and enacted through language use. At these moments of being stereotyped, Allan and Gabe were likely to be positioned in a less powerful status. The experience of being discriminated against caused Allan's decreasing investment in learning Chinese and also his being afraid of having his American identity overlooked. As He's (2008) CHL development framework recognizes the important role of agency in language learning, language learners can assume more powerful identities and negotiate the advantages and challenges of their multiple identities. In this study, Gabe reconstructed and envisioned his identity as an Asian American attorney to pursue social justice and increase the social representation of Asian American attorneys in the legal field.

When CHLLs grew up and entered college, they tended to construct an identity that was opposite to the group with which they were interacting. To be specific, their feeling of being an Asian was more prominent when they interacted with American people, while being an American was more prominent when they interacted with Chinese people. Such identity orientation is worthy of further exploration. Both participants agreed that there were some differences between themselves and other non-heritage Chinese language learners. Such differences chiefly stemmed from the CHLL's prior knowledge and cultural experience. Linguistically, CHLLs were found to understand certain vocabulary faster and deeper. Culturally, they considered their heritage identity as the distinguishable factor from their nonCHLL counterparts. These findings partly corroborated the previous literature on the uniqueness of HLLs (e.g., Carreira \& Kagan, 2018; Montrul, 2012). Their identities are more complex because their cultural and family background is unique. 
All participants had a deeper understanding of their identity than when they were in their childhood, which may have resulted from their growing life experience, especially having taken the Chinese classes. Specifically, Allan had a more comprehensive understanding of his identity by considering his origin, language proficiency, and connection to Chinese culture. Gabe not only identified himself as an Asian American but also prepared himself as an Asian American attorney in the future. Andrew had multiple identities with different emphases in different contexts. Such finding is aligned with He's $(2008,2016)$ assertion that CHLLs are constantly constructing their identity across time and space, in the process of socialization with other people such as Chinese language instructors and peers in school, and parents and other direct relatives at home.

The findings have inspired researchers to further consider the definition and scope of Chinese, as well as what it means to be a CHLL for those who have Southeast Asian American heritage (Li \& Duff, 2014). One of the major challenges was "the conflation of all Chinese home languages" (Duff \& Doherty, 2019, p. 150). In other words, what does Chinese mean to this group of participants if their heritage language or home language is different from the Chinese language they are learning in the classroom, which is Mandarin? Although they admitted that, or were positioned that they belonged to the category of CHLLs, the participants' use of various terminology to express their identities, such as Asian American, Chinese American, or Chinese, reflected their ideological conception and even tension. For example, even though Gabe had partial Chinese heritage, he never identified himself as Chinese. Andrew felt more connected to the China when his ancestors left the country around the 1940s to 1950s, rather than the China of today. Future research in language learning and identity construction of CHLLs with Southeast Asian heritage backgrounds may provide insights into the adoption of terminology and participant recruitment criteria. In other words, different learners may have their understanding of CHLL, while the conceptualization of the term CHLL by the researchers also impacts who should be included or excluded as research participants.

\section{Conclusion}

This study explored how adult CHLLs with Southeast Asian backgrounds attempt to negotiate their identities when they learned Chinese in their childhood, college, and after graduating from college. Detailed analysis and insights from the richness of information were presented. To make stronger comprehensive conclusions, longer time of data collection, more observations, and more participants are needed. Particularly, more participants from diverse backgrounds are necessary. For example, all participants in this study are undergraduate students or college graduates. Are there any differences in terms of their identity construction in the Southeast Asian heritage population who do not have higher education backgrounds?

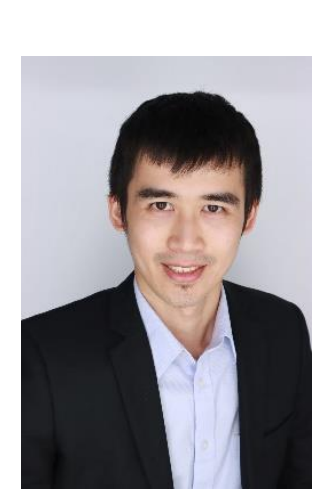

\section{About the Author}

Feng Liang is an assistant professor in the World Languages and Cultures program of Wittenberg University. He completed his Ph.D. in Educational Studies with concentration in Second Language Studies from the University of Cincinnati, with a graduate certificate in Asian Studies. His research interests include heritage language maintenance of Chinese languages, teaching and learning Chinese and Cantonese, and systemic functional linguistics. 


\section{References}

Blackledge, A., Creese, A., Baraç, T., Bhatt, A., Hamid, S., Wei, L., Lytra, V., Martin, P., Wu, C. J., \& Yağcioğlu, D. (2008). Contesting "language" as "heritage": Negotiation of identities in late modernity. Applied Linguistics, 29(4), 533-554.

https://doi.org/10.1093/applin/amn024

Braun, V., \& Clarke, V. (2006). Using thematic analysis in psychology. Qualitative research in psychology, 3(2), 77-101. https://doi.org/10.1191/1478088706qp063oa

Brinton, D., Kagan, O., \& Bauckus, S. (Eds.). (2008). Heritage language education. A new field emerging. Routledge.

Carreira, M., \& Kagan, O. (2018). Heritage language education: A proposal for the next 50 years. Foreign Language Annals, 51(1), 152-168. https://doi.org/10.1111/flan.12331

Corbin, J., \& Strauss, A. (2015). Basics of qualitative research: Techniques and procedures for developing grounded theory ( $4^{\text {th }}$ ed.). Sage.

Creswell, J. W. (2013). Qualitative inquiry and research design: Choosing among five approaches $\left(3^{\text {rd }}\right.$ edition). SAGE Publications.

Dai, J. H. E., \& Zhang, L. (2008). What are the CHL learners inheriting? Habitus of the CHL learners. In A. He \& Y. Xiao (Eds.), Chinese as a heritage language: Fostering rooted world citizenry (pp. 37-52). University of Hawaii Press.

DiCicco-Bloom, B., \& Crabtree, B. F. (2006). The qualitative research interview. Medical Education, 40(4), 314-321. https://doi.org/10.1111/j.1365-2929.2006.02418.x

Duff, P., \& Doherty, L. (2019). Learning "Chinese" as heritage language: Challenges, issues, and ways forward. In C.-R. Huang, Z. Jing-Schmidt, \& B. Meisterernst (Eds.), Routledge handbook of Chinese applied linguistics (pp. 149-164). NY: Routledge.

Duff, P., Liu, Y., \& Li, D. (2017). Chinese heritage language learning: Negotiating identities, ideologies, and institutionalization. In O. Kagan, M. Carreira, \& C. Chik (Eds.), Routledge handbook on heritage language education (pp. 409-422). NY: Routledge.

Francis, B., Mau, A., \& Archer, L. (2014). Speaking of identity? British-Chinese young people's perspectives on language and ethnic identity. In X. L. Curdt-Christiansen \& A. Hancock (Eds.), Learning Chinese in Diasporic Communities: Many pathways to being Chinese (pp. 203-218). John Benjamins.

He, A. W. (2008). An identity-based model for the development of Chinese as a heritage language. In A. He \& Y. Xiao (Eds.), Chinese as a heritage language: Fostering rooted world citizenry (pp. 109-124). University of Hawaii Press.

He, A. \& Xiao, Y. (Eds.). (2008). Chinese as a heritage language: Fostering rooted world citizenry. University of Hawaii Press.

He, A. W. (2012). Heritage language socialization. In A. Duranti, E. Ochs, \& B. B. Schieffelin (Eds.). The handbook of language socialization ( $1^{\text {st }}$ ed., pp. 587-609). Wiley-Blackwell.

He, A. W. (2016). Heritage language learning and socialization. In P. A. Duff \& S. May (Eds.), Language socialization: Encyclopedia of language and education (pp. 1-12). Springer.

Hesse-Biber, S. \& Leavy, P. (2011). The practice of qualitative research (2nd ed.). Sage. Hornberger, N. H. (Ed.). (2012). Educational linguistics: Critical concepts in linguistics, (Vol. 6). Routledge.

Hornberger, N. H., \& Wang, S. C. (2008). Who are our heritage language learners? Identity and biliteracy in heritage language education in the United States. In D. M. Brinton, O. Kagan \& S. Bauckus (Eds.), Heritage language education: A new field emerging (pp. 3-35). Routledge. 
Hsieh, H. F., \& Shannon, S. E. (2005). Three approaches to qualitative content analysis. Qualitative health research, 15(9), 1277-1288. https://doi.org/10.1177\%2F1049732305276687

Kim, S. Y., \& Chao, R. K. (2009). Heritage language fluency, ethnic identity, and school effort of immigrant Chinese and Mexico adolescents. Cultural Diversity and Ethnic Minority Psychology, 15(1), 27-37. https://doi.org/10.1037/a0013052

Kurniawan, B., \& Suprajitno, S. (2019). Chinese as a cultural capital: The case study of Chinese heritage language learners. $k @ t a, 21(1), 1-9$. https://doi.org/10.9744/kata.21.1.1-9

Lao, R. S., \& Lee, J. S. (2009). Heritage language maintenance and use among 1.5 generation Khmer college students. Journal of Southeast Asian American Education and Advancement, 4(1), 1-20. http://doi.org/10.7771/2153-8999.1094

Li, D., \& Duff, P. (2014). Chinese language learning by adolescents and young adults in the Chinese diaspora: Motivation, ethnicity, and identity. In X. L. Curdt-Christiansen \& A. Hancock (Eds.), Learning Chinese in diasporic communities: Many pathways to being Chinese (pp. 219-238). John Benjamins.

Liang, F., \& Shin, D. (2021). Heritage language maintenance of Chinese immigrant families: Perceptions, practices, and challenges. Bilingual Research Journal, 44(1), 23-38. https://doi.org/10.1080/15235882.2021.1922539

Liu, R. (2008). Maintaining Chinese as a heritage language in the United States: What really matters? Journal of Second Language Acquisition and Teaching, 15, 37-64.

Maloof, V. M., Rubin, D. L., \& Miller, A. N. (2006). Cultural competence and identity in cross-cultural adaptation: The role of a Vietnamese heritage language school. International Journal of Bilingual Education and Bilingualism, 9(2), 255-273. https://doi.org/10.1080/13670050608668644

Marks, A. K., Szalacha, L. A., Lamarre, M., Boyd, M. J., \& García Coll, C. (2007). Emerging ethnic identity and interethnic group social preferences in middle childhood: Findings from the Children of Immigrants Development in Context (CIDC) study. International Journal of Behavioral Development, 31(5), 501-513. https://doi.org/10.1177\%2F0165025407081462

Maxwell, J. A. (2013). Qualitative research design: An interactive approach (3rd ed.). Sage.

Merriam, S. B. (2010). Qualitative research and case study applications in education. Jossey-Bass Publishers.

Montrul, S. A. (2012). Is the heritage language like a second language? Eurosla Yearbook, 12(1), 1-29. https://doi.org/10.1075/eurosla.12.03mon

$\mathrm{Mu}, \mathrm{G}$. M. (2016). Looking Chinese and learning Chinese as a heritage language: The role of habitus. Journal of Language, Identity \& Education, 15(5), 293-305. https://doi.org/10.1080/15348458.2016.1214586

Mulhall, A. (2003). In the field: Notes on observation in qualitative research. Journal of Advanced Nursing, 41(3), 306-313. https://doi.org/10.1046/j.1365-2648.2003.02514.x

Norton, B. (2013). Identity and language learning: Extending the conversation (2nd ed.). Multilingual Matters.

Nowell, L. S., Norris, J. M., White, D. E., \& Moules, N. J. (2017). Thematic analysis: Striving to meet the trustworthiness criteria. International Journal of Qualitative Methods, 16(1), 1-13. https://doi.org/10.1177\%2F1609406917733847

Tran, A. (2008). Vietnamese language education in the United States. Language, Culture and Curriculum, 21(3), 256-268. https://doi.org/10.1080/07908310802385923

Withers, A. C. (2004). Hmong language and cultural maintenance in Merced, California. Bilingual Research Journal, 28(3), 425-461. https://doi.org/10.1080/15235882.2004.10162624 
Weger-Guntharp, H. (2006). Voices from the margin: Developing a profile of Chinese heritage language learners in the FL classroom. Heritage Language Journal, 4(1), 2946. http://doi.org/10.46538/hlj.4.1.2

Wright, W. E. (2007). The situation of the Khmer language in the United States. In J. T. Tsuchida, J. M. Benitez \& D. S. Toji (Eds.), Education, youth, leadership, labor: Asian Pacific American and Latino perspectives (pp. 113-150). Center for Asian Pacific American Studies, California State University, Long Beach.

Wright, W. E. (2010). Khmer as a heritage language in the United States: Historical sketch, current realities, and future prospects. Heritage Language Journal, 7(1), 117-147. https://doi.org/10.46538/hlj.7.1.6

Xiang, X. (2016) The teaching of Chinese to heritage language learners at the post-secondary level. In J. Ruan, J. Zhang, \& C. Leung (Eds.), Chinese Language Education in the United States, (pp. 167-194). Springer.

Yang, T. (2008). Hmong parents critical reflections on their children's heritage language maintenance. Journal of Southeast Asian American Education and Advancement, 3(1), 1-16. http://doi.org/10.7771/2153-8999.1113

Yin, R. K. (2013). Validity and generalization in future case study evaluations. Evaluation, 19(3), 321-332. https://doi.org/10.1177/1356389013497081

Yin, R. K. (2014). Case study research: Design and methods ( $5^{\text {th }}$ ed.). Sage Publications.

Yin, R. K. (2015). Qualitative research from start to finish ( $2^{\text {nd }}$ ed.). The Guilford Press.

Yu, S.-C. (2015). The relationships among heritage language proficiency, ethnic identity, and self-esteem. FIRE: Forum for International Research in Education, 2(2), 55-71. 


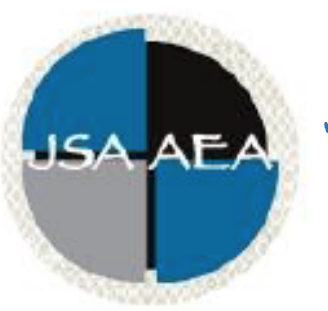

Vol.16 Iss.1 (2021)

\title{
Journal of Southeast Asian American Education and Advancement
}

\author{
www.JSAAEA.org
}

\section{Editor}

Dr. Wayne E. Wright

Purdue University

Associate Editors

Dr. Chhany Sak-Humphry

University of Hawaii at Manoa

Dr. Phitsamay Sychitkokhong Uy

University of Massachusetts, Lowell

\author{
Book Review Editor \\ Dr. Vichet Chhuon \\ University of Minnesota \\ Creative Works Editor \\ Bryan Thao Worra \\ Lao Assistance Center \\ Journal Manager \\ Vikrant Chap \\ Purdue University
}

\section{Editorial Review Board}

Dr. Steve Arounsack

California State University, Stanislaus

Dr. Sovicheth Boun

Salem State University

Dr. Virak Chan

Purdue University

Dr. Loan Dao

University of Massachusetts Boston

Dr. Linh Dang

KIPP DC Headquarters

Dr. Sophal Ear

Occidental College
Dr. Carl L. Bankston III

Tulane University

Dr. Phala Chea

Lowell Public Schools

Dr. George Chigas

University of Massachusetts, Lowell

Dr. Hien Duc Do

San Jose State University

Dr. Changming Duan

University of Missouri-Kansas City

Dr. Sothy Eng

Lehigh University 
Dr. Vincent K. Her

University of Wisconsin, Eau Claire

Dr. Nancy H. Hornberger

University of Pennsylvania

Dr. Peter Tan Keo

New York University

Dr. Yvonne Kwan

San Jose State University

Dr. Ravy Lao

California State University, Los Angeles

Dr. Stacey Lee

University of Wisconsin, Madison

Dr. Jacqueline Mac

Northern Illinois University

Dr. Bic Ngo

University of Minnesota

Dr. Leakhena Nou

California State University, Long Beach

Dr. Mark Pfeifer

SUNY Institute of Technology

Dr. Loan T. Phan

University of New Hampshire

Dr. Karen Quintiliani

California State University, Long Beach

Dr. Angela Reyes

Hunter College

The City University of New York

Dr. Fay Shin

California State University, Long Beach

Dr. Christine Su

College of San Mateo

Dr. Alisia Tran

Arizona State University

Dr. Khatharya Um

University of California, Berkeley

Dr. Kim Tran

University of California, Los Angeles,

Glendale Community College

Dr. Molly Wiebe

The University of Texas at Austin
Dr. Jeremy Hein

University of Wisconsin, Eau Claire

Dr. Peter Nien-Chu Kiang

University of Massachusetts, Boston

Dr. Kevin K. Kumashiro

University of Illinois, Chicago

Dr. Ha Lam

Independent Scholar

Dr. Jonathan H. X. Lee

San Francisco State University

Dr. Monirith Ly

Royal University of Phnom Penh

Dr. Sue Needham

California State University, Dominguez Hills

Dr. Max Niedzwiecki

Daylight Consulting Group

Dr. Clara Park

California State University, Northridge

Dr. Giang Pham

University of Massachusetts Amherst

Dr. Malaphone Phommasa

University of California Santa Barbara

Dr. Kalyani Rai

University of Wisconsin-Milwaukee

Dr. Cathy J. Schlund-Vials

University of Connecticut, Storrs

Dr. Nancy J. Smith-Hefner

Boston University

Dr. Yer J. Thao

Portland State University

Dr. Monica M. Trieu

Purdue University

Dr. Silvy Un

Saint Paul Public Schools

Dr. Linda Trinh Vo

University of California, Irvine

Dr. Varaxy Yi Borromeo

California State University, Fresno

Dr. Yang Sao Xiong

The University of Wisconsin-Madison

Dr. Zha Blong Xiong

University of Minnesota 


\section{Doctoral Student Editorial Review Board}

Diana Chandara

University of Minnesota-Twin Cities

Bao Diep

University of Minnesota-Twin Cities

Vanessa Sovanika Na

University of California San Diego

Khoi Nguyen

George Mason University

Hoa Nha Nguyen

Boston College

Linda Marie Pheng

University of Wisconsin-Madison

Latana Thaviseth

University of California Los Angeles

Melissa Vang

San Diego State University
Kassandra Chhay

University of Minnesota-Twin Cities

Annie BichLoan Duong

San Joaquin County Office of Education

Nielson Hul

Cornell University

Dung Minh Mao

University of Minnesota-Twin Cities

Thien-Huong Ninh

University of Southern California

Krissyvan Truong

Claremont Graduate University

Mai Vang

University of Massachusetts Boston

Thong Vang

University of Minnesota-Twin Cities

\section{Soua Xiong}

San Diego State University

Claremont Graduate University 